CLINICAL STUDY

\title{
Nitric oxide mediates abnormal responsiveness of thyroid arteries in methimazole-treated patients
}

\author{
Joaquín Ortega $^{1}$, José M Vila ${ }^{3}$, María Dolores Mauricio ${ }^{3}$, Gloria Segarra ${ }^{2}$, Pascual Medina ${ }^{3}$, Juan B Martínez-León ${ }^{1}$ \\ and Salvador Lluch ${ }^{3}$ \\ ${ }^{1}$ Department of Surgery, ${ }^{2}$ Hospital Clínico Research Unit and ${ }^{3}$ Department of Physiology, University of Valencia, 46010 Valencia, Spain \\ (Correspondence should be addressed to S Lluch, Departamento de Fisiología, Facultad de Medicina, Blasco Ibañez 17, 46010 Valencia, Spain; \\ Email: lluchs@post.uv.es)
}

\begin{abstract}
Objective: We studied the intervention of nitric oxide (NO), prostacyclin and endothelium-derived hyperpolarizing factor (EDHF) in mediating responses to acetylcholine in thyroid arteries from euthyroid and methimazole-treated (MT) patients.

Design and methods: Branches of the superior thyroid artery were obtained from 19 euthyroid patients and 17 MT patients (euthyroid at the time of surgery) undergoing total thyroidectomy or hemithyroidectomy. Artery rings were suspended in organ baths for isometric recording of tension.

Results and conclusions: Acetylcholine caused endothelium-dependent relaxation of greater magnitude in arteries from MT patients $\left(\mathrm{pD}_{2}\left(-\log \mathrm{EC}_{50}\right)\right.$ values were $7.68 \pm 0.19$ in euthyroid and $8.17 \pm 0.26$ in MT patients, $P<0.05)$. The relaxation was unaffected by indomethacin and was partially reduced by the NO-synthase inhibitor NG-monomethyl-L-arginine (L-NMMA). This reduction was higher in arteries from MT patients $(50 \pm 6 \%)$ as compared with euthyroid patients $(36 \pm 6 \%)(P<0.05)$. Inhibition of $\mathrm{K}^{+}$channels using apamin combined with charybdotoxin or high $\mathrm{K}^{+}$solution abolished the relaxation resistance to L-NMMA and indomethacin. The maximal contraction response to noradrenaline (as a percentage of the response to $100 \mathrm{mM} \mathrm{KCl}$ ) was lower in MT than in euthyroid patients $(57 \pm 10$ and $96 \pm 8$ respectively, $P<0.05)$. The hyporesponsiveness to noradrenaline in arteries from MT patients was corrected by L-NMMA. The results indicate that: (i) thyroid arteries from MT patients show an increased relaxation response to acethylcholine and a decreased contraction response to noradrenaline due to overproduction of NO; (ii) EDHF plays a prominent role in acetylcholine-induced relaxation through activation of $\mathrm{Ca}^{2+}$-activated $\mathrm{K}^{+}$channels; (iii) the abnormal endothelium-dependent responses in arteries from MT patients are not corrected by medical treatment.
\end{abstract}

European Journal of Endocrinology 152 551-556

\section{Introduction}

Hyperthyroidism is associated with marked effects on the cardiovascular system including high cardiac output, increased heart rate, and a fall in peripheral vascular resistance (1). In addition, hyperthyroidism is characterized by alterations in vascular responsiveness. Experiments with aortic rings from hyperthyroid rats show reduced responses to contractile agents $(2-4)$ and enhanced endothelium-dependent relaxation to acetylcholine (4) compared with euthyroid rats.

The mechanism by which thyroid dysfunction alters vascular responsiveness is still unknown. A recent study in rat isolated renal artery rings has shown that after short treatment (single injection) with triiodothyronine (T3), acetylcholine-induced relaxation mediated by endothelium-derived nitric oxide (NO) and by the endothelium-derived hyperpolarizing factor (EDHF) was significantly enhanced compared with controls. Following 8 weeks of treatment with T3, EDHF-mediated relaxation was impaired, whereas NOmediated relaxation remained enhanced (5). These results show differences in vascular responses between acute and chronic hyperthyroidism and indicate that both NO and EDHF are responsible for the increased endothelium-dependent relaxation in hyperthyroidism.

In humans during acetylcholine infusion, forearm blood flow, measured by plethysmography, increased more in hyperthyroid patients than in control subjects (6). In addition, untreated hyperthyroid patients showed a more pronounced fall in forearm blood flow after inhibition of basal NO synthesis by intra-arterial infusion of the NO-synthase inhibitor NG-monomethyl-L-arginine (L-NMMA). These results in human resistance vessels strongly suggest that NO might play a key role in the vascular changes observed in thyroid dysfunction. Moreover, after treatment with the antithyroid drug, methimazole, thyroid hormone levels, 
basal forearm blood flow, and vasodilatation in response to acetylcholine were restored to normal, thus supporting the conclusion that thyroid hormone elevation is specifically responsible for the vascular abnormalities observed in untreated hyperthyroidism (6).

The endothelium-NO system of human thyroid arteries remains largely unexplored. A recent study from our laboratory has shown that in human thyroid arteries from multiorgan donors the endothelium modulates responses to acetylcholine and noradrenaline through the release of $\mathrm{NO}$ and EDHF (7). The EDHF component involved activation of $\mathrm{Ca}^{2+}$-dependent $\mathrm{K}^{+}$channels sensitive to the $\mathrm{K}^{+}$channel blockers charybdotoxin and apamin. No data are available concerning endothelial function in thyroid arteries from euthyroid patients and patients with Graves' disease treated with methimazole. Such data would be relevant in the understanding of the regulation of intrathyroidal blood after medical treatment and the mechanisms underlying the vascular abnormalities in thyroid disease. Accordingly, the aim of the present study was to extend our previous observations by determining the responses to acetylcholine and noradrenaline of thyroid arteries from euthyroid patients and from hyperthyroid patients with Graves' disease after treatment with methimazole.

\section{Materials and methods}

\section{Subjects}

Tissue samples were obtained from two groups of patients undergoing subtotal thyroidectomy or hemithyroidectomy. One group included 19 euthyroid patients (free thyroxine $1.24 \pm 0.04 \mathrm{ng} / \mathrm{dl}$, thyroid stimulating hormone $2.8 \pm 0.4 \mathrm{mIU} / \mathrm{l})$ affected by multinodular goiters causing compression and obstructive symptoms (14 women, five men; $54 \pm 3$ years). The other group included 17 patients affected by Graves' disease (15 women, two men; $44 \pm 4$ years), who had been hyperthyroid for $4 \pm 1.8$ months according to their medical history. Indications for surgery in this group included the appearance of cyclic phases of exacerbation of the disease. The hyperthyroid patients had received methimazole for at least 12 months and were euthyroid at the time of surgery (free thyroxine $1.14 \pm 0.04 \mathrm{ng} / \mathrm{dl}$, thyroid stimulating hormone $2.6 \pm 0.6 \mathrm{mIU} / \mathrm{l})$. These patients are referred to as methimazole-treated (MT) patients. The study was approved by the ethical committee of our institution and each patient gave informed written consent.

\section{In vitro experiments}

Glandular branches of the superior thyroid artery were removed and cut into rings $(3 \mathrm{~mm}$ in length, 1 to $1.5 \mathrm{~mm}$ outer diameter) and placed in refrigerated $\left(4^{\circ} \mathrm{C}\right)$ modified Krebs Henseleit solution of the following composition (in $\mathrm{mmol} / \mathrm{l}$ ): $\mathrm{NaCl}, 115 ; \mathrm{KCl}, 4.6$; $\mathrm{MgCl}_{2} \cdot 6 \mathrm{H}_{2} \mathrm{O}, 1.2 ; \mathrm{CaCl}_{2}, 2.5 ; \mathrm{NaHCO}_{3}, 25$; glucose, 11.1 and disodium EDTA, 0.01. Each artery ring was prepared for isometric tension recording as previously described (7). Changes in isometric force were recorded on a Macintosh computer (Apple Computer, Cupertino, CA, USA) by the use of Chart version 3.4/s software and a MacLab/8e data adquisition system (ADInstruments, Mountain View, CA, USA). In some experiments, the endothelium was removed by inserting a stainlesssteel wire into the lumen. An optimal resting tension of $2 \mathrm{~g}$ was applied. The rings were allowed to attain a steady level of tension during a 2- to 3-h accomodation period before testing.

The relaxation response to acetylcholine $(1 \mathrm{nmol} / \mathrm{l}$ to $1 \mu \mathrm{mol} / \mathrm{l})$ was investigated in arteries precontracted with noradrenaline to $40-50 \%$ of the contraction induced by $100 \mathrm{mmol} / \mathrm{l} \mathrm{KCl}$ under the following conditions: (i) in the absence of inhibitors (control response); (ii) in the presence of indomethacin $(10 \mu \mathrm{mol} / \mathrm{l})$ to inhibit the production of prostacyclin (PGI2); (iii) in the presence of indomethacin and LNMMA $(100 \mu \mathrm{mol} / \mathrm{l})$ to inhibit the production of PGI2 and NO synthase respectively; (iv) in the presence of indomethacin, L-NMMA and $\mathrm{KCl}(20 \mathrm{mmol} / \mathrm{l})$ to inhibit the production of PGI2, NO synthase and $\mathrm{K}^{+}$channel activity; ( $\mathrm{v}$ ) in the presence of methimazole (1 $\mu \mathrm{mol} / \mathrm{l})$.

To examine the nature of $\mathrm{K}^{+}$channel activation, the relaxation response to acetylcholine was obtained in the presence of indomethacin plus L-NMMA combined with one of the following inhibitors: iberiotoxin $(0.1 \mu \mathrm{mol} / \mathrm{l})$, an inhibitor of large-conductance $\mathrm{Ca}^{2+}$ activated $\mathrm{K}^{+}$channels; charybdotoxin $(0.1 \mu \mathrm{mol} / \mathrm{l})$, an inhibitor of both large- and intermediate-conductance $\mathrm{Ca}^{2+}$-activated $\mathrm{K}^{+}$channels; apamin $(1 \mu \mathrm{mol} / \mathrm{l})$, an inhibitor of small-conductance $\mathrm{Ca}^{2+}$-activated $\mathrm{K}^{+}$ channels; glibenclamide $(10 \mu \mathrm{mol} / \mathrm{l})$, a selective blocker of ATP-sensitive $\mathrm{K}^{+}$channels. Control (in the absence of inhibitors) and experimental (after incubation for $20 \mathrm{~min}$ with inhibitors) responses were obtained from separate preparations. Concentration-response curves for noradrenaline were determined in the absence and in the presence of L-NMMA $(100 \mu \mathrm{mol} / \mathrm{l})$.

\section{Chemicals}

All substances were purchased from Sigma Chemical Co. (St Louis, MO, USA). Stock solutions of the drugs were freshly prepared every day.

\section{Data analysis}

All values are expressed as means \pm S.E.M. Contraction was expressed as a percentage of the response to $\mathrm{KCl}$ (100 mmol/l). Relaxation was expressed as a percentage of inhibition of noradrenaline-induced contrac- 
tion. $\mathrm{EC}_{50}$ values (concentration of agonist producing half-maximum effect) were expressed as $\mathrm{pD}_{2}(-\log$ $\left.\mathrm{EC}_{50}\right)$. The $\mathrm{pD}_{2}$ values were compared by an unpaired $t$-test and two-way analysis of variance (ANOVA). $n$ values are presented as the number of patients. Statistical significance was accepted at $P<0.05$.

\section{Results}

Acetylcholine caused concentration-dependent relaxation which was of greater magnitude in the arteries from MT patients (Fig. 1, Table 1). There was no significant difference in the response to the endotheliumindependent vasodilator sodium nitroprusside (Table 1). In endothelium-denuded rings the relaxation response to acetylcholine was abolished. L-NMMA reduced acetylcholine-induced relaxation in endothelium-intact rings; the inhibition was greater in arteries from MT patients (50\% in MT vs $36 \%$ in euthyroid patients, $P<0.05)$. Indomethacin did not change the relaxation response to acetylcholine.

The remaining endothelium-dependent relaxation response after exposure to L-NMMA and indomethacin was further reduced by $20 \mathrm{mmol} / \mathrm{l} \mathrm{KCl}$ or the combination of charybdotoxin and apamin whereas apamin with iberiotoxin had no significant effects (Fig. 2). Inhibition of relaxation by charybdotoxin and apamin was greater in arteries from MT patients compared with euthyroid patients $(90 \%$ in MT versus $65 \%$ in euthyroid patients, $P<0.05)$. Incubation with apamin, charybdotoxin, iberiotoxin or the blocker of ATP-sensitive $\mathrm{K}^{+}$channels, glibenclamide, had no effect on acetylcholine-induced relaxation (not shown).

There was a marked hyporesponsiveness of thyroid arteries from MT patients to noradrenaline (Fig. 3, Table 1). L-NMMA increased the maximal contractile responses in arteries from the two groups; however, the increment was more pronounced in arteries from MT patients (135\% in MT vs 35\% in euthyroid patients, $P<0.05)$. There was no significant difference in the contractile response to $100 \mathrm{mmol} / \mathrm{l} \mathrm{KCl}$ between the arteries from euthyroid and MT patients (1950 $\pm 221 \mathrm{mg}$ vs $2092 \pm 215 \mathrm{mg}, n=12$ for each group, $P>0.05)$. Methimazole had no effect per se on arteries from euthyroid and MT patients. This was assessed by the absence of effects of methimazole
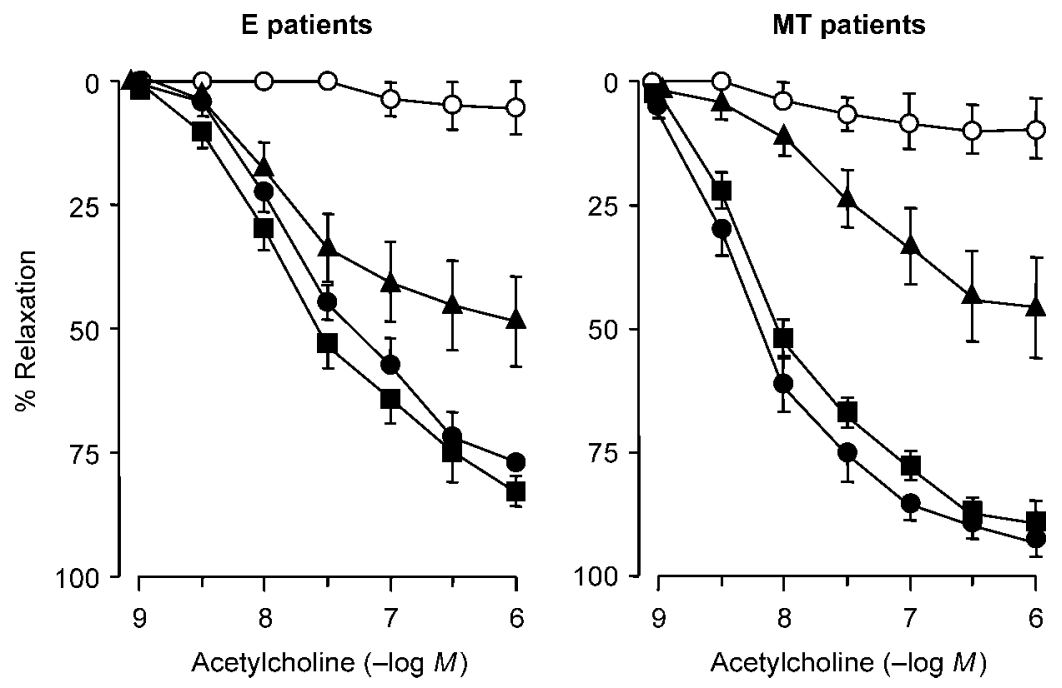

Figure 1 Effects of endothelium removal $(n=9 ; \bigcirc)$, indomethacin $(n=7 ; \boldsymbol{\square})$, and L-NMMA $(n=7 ; \boldsymbol{\Lambda})$ on the relaxation response to acetylcholine in thyroid arteries from euthyroid $(E)$ and methimazole-treated (MT) patients. $\bullet$, endothelium intact group $(n=9)$.

Table $1 \mathrm{pD}_{2}$ and maximal response values for acetylcholine, sodium nitroprusside and noradrenaline in arteries from euthyroid and methimazole-treated (MT) patients. Number of patients is shown in parentheses.

\begin{tabular}{|c|c|c|c|c|}
\hline \multirow[b]{2}{*}{ Treatment } & \multicolumn{2}{|c|}{ Euthyroid } & \multicolumn{2}{|c|}{ MT } \\
\hline & $\mathrm{pD}_{2}$ & $\operatorname{Emax}(\%)$ & $\mathrm{pD}_{2}$ & $\operatorname{Emax}(\%)$ \\
\hline \multicolumn{5}{|l|}{ Acetylcholine } \\
\hline Control & $7.68 \pm 0.19$ & $80 \pm 6(9)$ & $8.17 \pm 0.26 \dagger$ & $96 \pm 2 \dagger(10)$ \\
\hline L-NMMA & $7.91 \pm 0.35$ & $51 \pm 9 *(7)$ & $7.47 \pm 0.19^{\star}$ & $48 \pm 8^{*}(7)$ \\
\hline Methimazole & $7.58 \pm 0.20$ & $82 \pm 8(4)$ & $8.21 \pm 0.35 \dagger$ & $96 \pm 3+(4)$ \\
\hline Sodium nitroprusside & $8.16 \pm 0.46$ & $100(6)$ & $8.28 \pm 0.34$ & $100(6)$ \\
\hline \multicolumn{5}{|l|}{ Noradrenaline } \\
\hline Control & $5.83 \pm 0.18$ & $96 \pm 8(7)$ & $5.45 \pm 0.11 \dagger$ & $57 \pm 10 \dagger(7)$ \\
\hline L-NMMA & $6.01 \pm 0.10$ & $130 \pm 13^{*}(7)$ & $5.53 \pm 0.16 \dagger$ & $134 \pm 15^{*}(7)$ \\
\hline
\end{tabular}

$\mathrm{pD}_{2}$, negative logarithm of molar concentration required to produce half-maximal response.

${ }^{\star} P<0.05$ vs control; $\uparrow P<0.05$ vs euthyroid patients. 


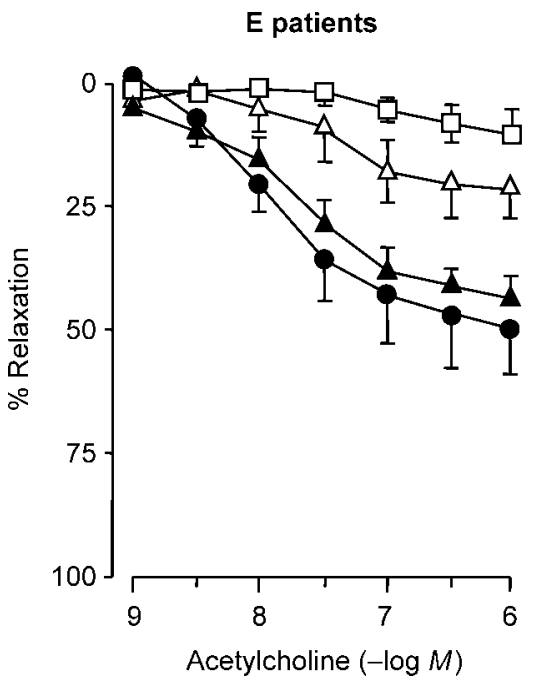

E patients

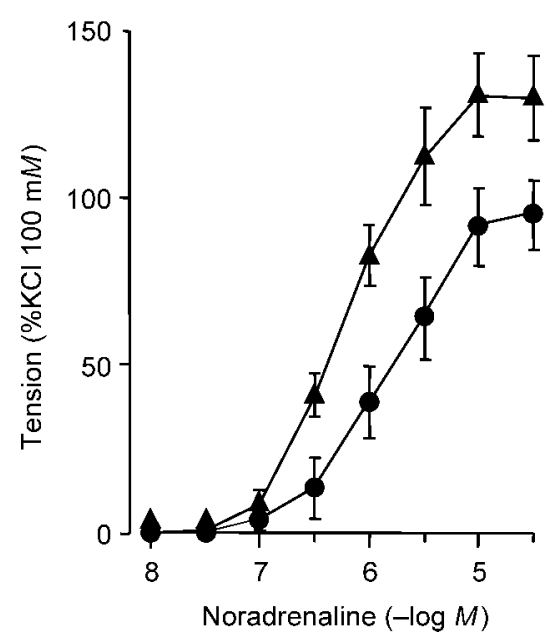

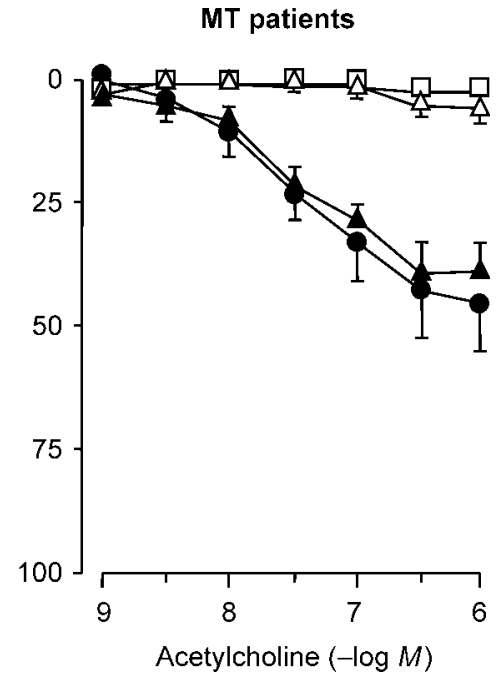

MT patients

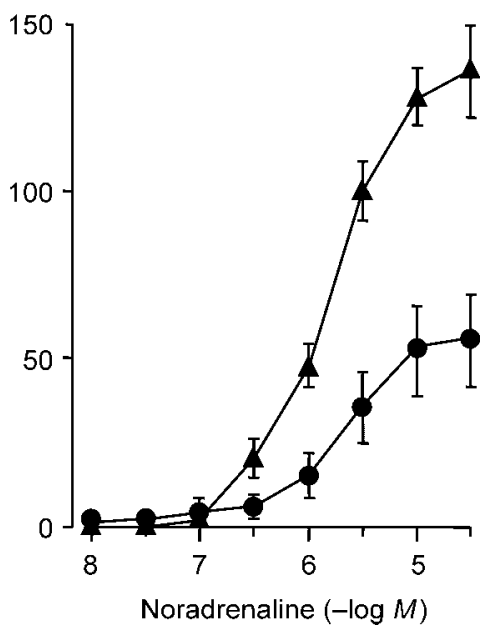

Figure 2 Relaxation response to acetylcholine in the absence (control, $n=8 ; \bullet$ ) and in the presence of $\mathrm{KCl} 20 \mathrm{mM}(n=5 ; \square)$, apamin plus charybdotoxin $(n=6 ; \Delta)$ and apamin plus iberiotoxin $(n=6 ; \boldsymbol{\Lambda})$ in thyroid arteries from euthyroid (E) and methimazole-treated (MT) patients. L-NMMA and indomethacin were present throughout.
Figure 3 Contractile responses to noradrenaline in the absence (control, $n=7 ; \bullet$ ) and in the presence of L-NMMA $(n=7 ; \boldsymbol{\Lambda})$ in thyroid arteries from euthyroid $(E)$ and methimazoletreated (MT) patients.
( $1 \mu \mathrm{mol} / \mathrm{l}$ ) on acethylcoline-induced relaxation (Table 1) and by the lack of relaxing effect (less than $10 \%$ ) of methimazole $(10 \mathrm{nmol} / \mathrm{l}$ to $5 \mu \mathrm{mol} / \mathrm{l})$ on arteries contracted with noradrenaline.

\section{Discussion}

The present results in human thyroid arteries reveal that the relaxation response to acetylcholine was significantly greater in arteries from MT patients. In addition, the reduction by L-NMMA of the acetylcholine-induced relaxation was higher in arteries from MT patients, thus suggesting that a greater release of NO was involved. The remaining relaxation, insensitive to L-NMMA and indomethacin, may result from the release by acetylcholine of EDHF (8). The involvement of NO and EDHF in acetylcholine-induced relaxation has recently been observed in the isolated renal artery from hyperthyroid rats (5).
Our results in thyroid arteries from patients indicate that the EDHF component involves activation of $\mathrm{Ca}^{2+}$ dependent $\mathrm{K}^{+}$channels sensitive to charybdotoxin and apamin, a finding similar to that observed in thyroid arteries from donors (7). The nature and mechanisms of action of EDHF remain unknown. Several candidates for EDHF have been proposed including endothelium-derived $\mathrm{K}^{+}$ions (9), epoxyeicosatrienoic acid (10), hydrogen peroxide (11) and C-type natriuretic peptide (12). In human left internal mammary artery, the EDHF is 11,12-epoxyeicosatrienoic acid produced by one or more isoforms of cytochrome P450, and accounts for $40 \%$ of endothelium-dependent relaxation (13). Experiments in liver microsomes suggest a metabolism-dependent inhibition of P450 enzymes by methimazole $(14,15)$. In the present study, we did not determine whether cytochrome P450 enzymes play a role in endothelium-dependent relaxation of human thyroid arteries and therefore have no direct evidence that long treatment with methimazole inhibited these 
enzymes. However, if methimazole was an EDHF inhibitor in our experiments, the acetylcholine relaxation response which was insensitive to L-NMMA and indomethacin should have been reduced in thyroid arteries from MT patients.

An important feature of the present results is that although the hyperthyroid patients were euthyroid at the time of surgery, the responsiveness of thyroid arteries was clearly abnormal. This implies that abnormal endothelium-dependent responses of arteries from MT patients can be observed when plasma levels of thyroid hormones have been corrected by treatment. The observation, however, does not rule out a possible relationship between thyroid hormone levels and endothelium dysfunction in other vascular beds. In relation to this, it has been shown that the abnormal responsiveness of human forearm resistance vessels of hyperthyroid patients is corrected when euthyroidism is restored by medical treatment (6). In support of our results in thyroid arteries, an increased blood flow of the superior thyroid artery has been demonstrated in patients with Graves' disease, maintained in a euthyroid state with methimazole, prior to thyroid surgery (16). The increase in blood flow in the superior thyroid artery is positively correlated with microvessel density (17) and with vascular endothelial growth factor expression in hyperplasic follicular cells (18). These previous reports, together with the present results, indicate that vascularity in the thyroid gland does not parallel the methimazole-induced normalization of thyroid hormone levels, and that responsiveness of thyroid vessels does not follow the pattern of forearm resistance vessels. The abnormal response of thyroid vessels could be the result of sustained vascular expansion and endothelial cell proliferation caused by exposure to excess thyroid hormones during the period of time preceding medical therapy. These changes would lead to overproduction of NO and EDHF. In support of this proposal it has been shown in patients undergoing thyroid surgery that NO-synthase is expressed in thyroid vascular endothelial cells and in thyroid follicular cells and its levels are higher in hyperthyroid patients (euthyroid at the time of surgery) compared with euthyroid patients (19). Recent experiments in the rat have shown that after 8 weeks treatment with T3, endothelial NOsynthase expression was markedly enhanced in the aorta and was associated with an increase in NOmediated relaxation in the renal artery (5). These effects are probably due to the increased fluid shear stress at the endothelial surface (20). In contrast to the results observed in the rat renal artery (5), EDHFmediated relaxation was enhanced in MT patients. This may also be the consequence of a chronic elevation in shear stress, as this stimulus is known to enhance the expression of potassium channels on endothelial cells (21).

We observed a decreased contractile response to noradrenaline in arteries from MT patients. Inhibition of
NO-synthase augmented the contractile responses. This effect is attributed to the inhibition by L-NMMA of the depressant influence of endothelial NO released by noradrenaline through stimulation of $\alpha 2$ adrenoceptors on endothelial cells (22) or through indirect mechanisms involving a signal conducted from smooth muscle to adjacent endothelial cells (23). The magnitude of the effect of L-NMMA on contraction elicited by noradrenaline was greater in arteries from MT patients thus indicating increased endothelial NO production. It is possible that EDHF is also formed after noradrenaline-induced contraction (24). The study of this possibility has not been attempted in the present report.

The design of our in vitro experiments does not allow the study of the long-term effects of methimazole. Under conditions of acute exposure, methimazole failed to induce changes in contracted and noncontracted arteries. The range of concentrations of methimazol used $\left(10^{-8}-3 \times 10^{-6} \mathrm{~mol} / \mathrm{l}\right)$ include the mean intrathyroid methimazole concentration $(300 \mathrm{ng} / \mathrm{g}$ thyroid tissue) determined, prior to subtotal thyroid resection, in patients with Graves' disease (euthyroid at the time of surgery) treated with methimazole for 11.7 months (25).

In conclusion, the results indicate that: (i) thyroid arteries from MT patients (euthyroid at time of surgery) show an increased relaxation response to acetylcholine and a decreased contraction response to noradrenaline due to overproduction of NO; (ii) EDHF plays a prominent role in acetylcholine-induced relaxation through activation of $\mathrm{Ca}^{2+}$-activated $\mathrm{K}^{+}$channels; (iii) the abnormal endothelium-dependent responses in arteries from MT patients are not corrected by medical treatment.

\section{Acknowledgements}

This work was supported by the Ministerio de Ciencia y Tecnologia (BFI 2003-01 412), Generalitat Valenciana and Fondo de Investigaciones Sanitarias (023045).

\section{References}

1 Klein I \& Ojamaa K. Thyroid hormone and the cardiovascular system. New England Journal of Medicine $2001344501-509$.

2 Scivoletto R, Fortes ZB \& Garcia-Leme J. Thyroid hormones and vascular reactivity: role of the endothelial cell. European Journal of Pharmacology $1986129271-278$.

3 Gunasekera RD \& Kuriyama H. The influence of thyroid states upon responses of the rat aorta to catecholamines. British Journal of Pharmacology $199099541-547$.

4 McAllister RM, Grossenburg VD, Delp MD \& Laughlin MH. Effects of hyperthyroidism on vascular contractile and relaxation responses. American Journal of Physiology 1998274 E946-E953.

5 Bussemaker E, Popp R, Fisslthaler B, Larson CM, Fleming I, Busse R \& Brandes RP. Hyperthyroidism enhances endotheliumdependent relaxation in the rat renal artery. Cardiovascular Research $200359181-188$. 
6 Napoli R, Biondi B, Guardasole V, Matarazzo M, Pardo F, Angelini V, Fazio S \& Sacca L. Impact of hyperthyroidism and its correction on vascular reactivity in humans. Circulation $20011043076-3080$.

7 Torondel B, Vila JM, Segarra G, Lluch P, Medina P, MartinezLeon J, Ortega J \& Lluch S. Endothelium-dependent responses in human isolated thyroid arteries from donors. Journal of Endocrinology $2004181379-384$.

8 Feletou M \& Vanhoutte PM. Endothelium-dependent hyperpolarization of canine coronary smooth muscle. British Journal of Pharmacology $198893515-524$.

9 Edwards G, Dora KA, Gardener MJ, Garland CJ \& Weston AH. K is an endothelium-derived hyperpolarizing factor in rat arteries. Nature 1998396 269-272.

10 Campbell WB, Gebremedhin D, Pratt PF \& Harder DR Identification of epoxyeicosatrienoic acids as endothelium-derived hyperpolarizing factors. Circulation Research 199678 415-423.

11 Matoba T, Shimokawa H, Nakashima M, Hirakawa Y, Mukai Y, Hirano K, Kanaide H \& Takeshita A. Hydrogen peroxide is an endothelium-derived hyperpolarizing factor in mice. Journal of Clinical Investigation $2000 \mathbf{1 0 6} 1521-1530$.

12 Chauhan SD, Nilsson H, Ahluwalia A \& Hobbs AJ. Release of Ctype natriuretic peptide accounts for the biological activity of endothelium-derived hyperpolarizing factor. PNAS $2003 \mathbf{1 0 0}$ 1426-1431.

13 Archer SL, Gragasin FS, Wu X, Wang S, McMurtry S, Kim DH, Platonov M, Koshal A, Hashimoto K, Campbell WB, Falck JR \& Michelakis ED. Endothelium-derived hyperpolarizing factor in human internal mammary artery is 11,12-epoxyeicosatrienoic acid and causes relaxation by activating smooth muscle BKCa channels. Circulation $2003 \mathbf{1 0 7} 769-776$.

14 Kedderis GL \& Rickert DE. Loss of rat liver microsomal cytochrome P-450 during methimazole metabolism. Role of flavincontaining monooxygenase. Drug Metabolism and Disposition $19851358-61$.

15 Guo Z, Raeissi S, White RB \& Stevens JC. Orphenadrine and methimazole inhibit multiple cytochrome P450 enzymes in human liver microsomes. Drug Metabolism and Disposition 1997 25 390-393.

16 Huang SM, Chow NH, Lee HL \& Wu TJ. The value of color flow Doppler ultrasonography of the superior thyroid artery in the surgical management of Graves' disease. Archives of Surgery 2003138 146-151.

17 Castagnone D, Rivolta R, Rescalli S, Baldini MI, Tozzi R \& Cantalamessa L. Color Doppler sonography in Graves' disease: value in assessing activity of disease and predicting outcome. American Journal of Roentgenology 1996166 203-207.

18 Nagura S, Katoh R, Miyagi E, Shibuya M \& Kawaoi A. Expression of vascular endothelial growth factor (VEGF) and VEGF receptor-1 (Flt-1) in Graves' disease possibly correlated with increased vascular density. Human Pathology 200132 $10-17$.

19 Colin IM, Kopp P, Zbaren J, Haberli A, Grizzle WE \& Jameson JL. Expression of nitric oxide synthase III in human thyroid follicular cells: evidence for increased expression in hyperthyroidism. European Journal of Endocrinology 1997136 649-655.

20 Busse R \& Fleming I. Pulsatile stretch and shear stress: physical stimuli determining the production of endothelium-derived relaxing factors. Journal of Vascular Research 199835 73-84.

21 Hoger JH, Ilyin VI, Forsyth S \& Hoger A. Shear stress regulates the endothelial Kir2.1 ion channel. PNAS $2002997780-7785$.

22 Angus JA, Cocks TM \& Satoh K. The alpha adrenoceptors on endothelial cells. Federation Proceedings $1986452355-2359$.

23 Dora KA, Doyle MP \& Duling BR. Elevation of intracellular calcium in smooth muscle causes endothelial cell generation of NO in arterioles. PNAS 199794 6529-6534.

24 Dora KA, Hinton JM, Walker SD \& Garland CJ. An indirect influence of phenylephrine on the release of endothelium-derived vasodilators in rat small mesenteric artery. British Journal of Pharmacology $2000129381-387$.

25 Paschke R, Vogg M, Kristoferitsch R, Aktuna D, Wawschinek O, Eber $\mathrm{O} \&$ Usadel $\mathrm{KH}$. Methimazole has no dose-related effect on the intensity of the intrathyroidal autoimmune process in relapsing Graves' disease. Journal of Clinical Endocrinology and Metabolism 199580 2470-2474.

Received 9 December 2004

Accepted 17 January 2005 